\title{
Immunohistochemical studies of the enteric nervous system and interstitial cells of Cajal in the canine stomach
}

\begin{abstract}
Authors:
Colin Musara ${ }^{1}$

Camille Vaillant ${ }^{2}$

Affiliations:

${ }^{1}$ Department of Preclinical

Veterinary Studies, University

of Zimbabwe, Zimbabwe

${ }^{2}$ Department of Veterinary

Preclinical Studies, University

of Liverpool, United Kingdom
\end{abstract}

Correspondence to:

Colin Musara

Email:

preclinical@vet.uz.ac.zw

Postal address:

PO Box MP 167, Mount

Pleasant, Zimbabwe

Dates:

Received: 04 Sept. 2012

Accepted: 21 Dec. 2012

Published: 05 Mar. 2013

How to cite this article: Musara, C. \& Vaillant, C., 2013, 'Immunohistochemical studies of the enteric nervous system and interstitial cells of Cajal in the canine stomach', Onderstepoort Journal of Veterinary Research 80(1), Art. \#518, 4 pages. http://dx.doi.org/10.4102/ ojvr.v80i1.518

\section{Copyright:}

(C) 2013. The Authors.

Licensee: AOSIS

OpenJournals. This work

is licensed under the

Creative Commons

Attribution License.
Read online:
The distribution of interstitial cells of Cajal (ICC), the probable pacemakers in gastrointestinal motility, was investigated using an antigenic marker of gastric ICC known as C-Kit. Antiserum raised against the general neuronal marker protein gene peptide 9.5 (PGP) as well as the nitrergic neuronal marker neuronal nitric oxide synthase (nNOS) were used to investigate the distribution of gastric nerves. Polyclonal goat anti-human C-Kit was reliable in labelling ICC in the stomach. Two classes of ICC were identified according to their distribution: ICC-MY distributed around the periphery of myenteric ganglia and ICC-IM in the circular and longitudinal muscle layers. The neuronal marker PGP was reliably consistent in revealing the density and distribution of the enteric nervous system. Density of nerve fibres was higher in circular smooth muscle than in longitudinal smooth muscle. From nNOS immunohistochemistry, it is evident that inhibitory (nitrergic) nerves constitute a substantial fraction of the enteric nervous system.

\section{Introduction}

The canine stomach is divided into three parts, namely, the fundus, corpus and antrum. The fundus, by adaptive relaxation, is responsible for storage of ingesta whereas the corpus acts in unision with the antrum to mix and grind food particles before propelling them aborally. These functions rely on an efficient gastric motor system composed of pacemaker cells, neurons and smooth muscle cells. The gastric pacemaker located in the greater curvature of the corpus sets the basic electrical rhythm upon which contraction is superimposed. The origin of electrical activity in gastric smooth muscle is not known for certain but available evidence indicates involvement of interstitial cells of Cajal (ICC) (Hall et al. 1993; Huizinga et al. 1995; Sanders, Don Koh \& Ward 2006; Ward et al. 1995). These are small fusiform or stellate cells with prominent nuclei and arborisations that intertwine to form a network within the gastrointestinal musculature (Sanders 1996) and myenteric plexus (Burns et al. 1996).

Regulation and integration of gastric motility is mainly by the enteric nervous system with extrinsic sympathetic and parasympathetic nerves playing a role in modulation only. Motor nerves may be either excitatory or inhibitory. The interplay between these opposing actions determines gastric motility. Excitatory neurons for gastric smooth muscle include those secreting acetylcholine, substance $\mathrm{P}$, enkephalin and galanin whereas those releasing vasoactive intestinal polypeptide, cholecystokinin, somatostatin and neurotensin are inhibitory. Recently a subpopulation of neurons producing nitric oxide has been identified in the gastrointestinal tract (Moncada, Palmer \& Higgs 1991). Nitric oxide is an important mediator of relaxation of stomach smooth muscle (Li \& Rand 1990). It is synthesised from L-arginine in a reaction catalysed by neuronal nitric oxide synthase (nNOS). After synthesis, nitric oxide diffuses out to exert its biological effects via the second messenger molecule cyclic guanosine monophosphate.

Disturbances of motor function are common in mammalian gastrointestinal disorders (Lyford et al. 2002). In the dog, for example, gastric dilatation-volvulus is an acute disease characterised by gastric retention, accumulation of gas in the stomach, gastric dilatation and twisting of the stomach about its longitudinal axis (Burrows \& Ignazewski 1990). The objective of the present study was to investigate the normal morphology of the motor-regulating system in the canine stomach, namely ICC and the enteric neurons. This would contribute towards establishing a morphological basis for diagnosis of congenital as well as degenerative motor deficits of the stomach and possibly tumours of ICC.

\section{Materials and methods}

ICC express proteins which are useful markers in immunohistochemical studies of non-living tissues. One such protein is C-Kit which is involved in the growth, differentiation and migration of ICC (Rottapel et al. 1995). The general marker for the enteric nervous system is protein gene 
peptide 9.5 (Krammer et al. 1993; Thompson et al. 1983), which occurs in large amounts in the neurons of the vertebrate nervous system. Expression of neuronal nitric oxide synthase in nitric oxide-producing neurons allows the enzyme to be used as a marker in immunohistochemical studies (Bredt \& Snyder 1990).

Tissue samples from the corpus and antrum of the stomach were collected from nine dogs during surgery. The breeds of dogs included a Bull Mastiff, an Irish Setter, a Jack Russell, a Collie and six crossbreeds. Samples were collected in phosphate-buffered saline (PBS) maintained at $4{ }^{\circ} \mathrm{C}$. Each sample was divided into two parts for preparation of fixed and unfixed sections. For unfixed tissue, portions were cut from each sample under a dissecting microscope, embedded in optimal cutting temperature compound (OCT, MILES Company) and snap-frozen in isopentone cooled with liquid nitrogen. The frozen tissue was stored in a freezer at $-40{ }^{\circ} \mathrm{C}$ until further use. Fixed tissue was prepared by immersing the samples for $24 \mathrm{~h}$ in freshly prepared $4 \%$ formaldehyde in $0.1 \mathrm{M}$ sodium cacodylate buffer at $\mathrm{pH} 7.4$ followed by cryopreservation in $20 \%$ sucrose-sodium cacodylate buffer for another $24 \mathrm{~h}$ after which samples were dissected, snapfrozen and stored as for unfixed tissue.

All sections for immunohistochemistry were pre-treated with $0.3 \%$ hydrogen peroxide in pure ethanol for $20 \mathrm{~min}$ to block endogenous peroxidase activity (Vanderwiden et al. 1996). Primary and secondary antisera were diluted in PBS with $2 \%$ bovine serum albumin and $0.25 \%$ sodium azide. The horseradish peroxidase used in this study was diluted in PBS only.

Each experiment involved four incubations; a 24-hour incubation of samples at $4{ }^{\circ} \mathrm{C}$ with primary anti serum, followed by a one-hour incubation with biotinylated secondary antiserum at room temperature to trace sites of bound antibody. Sites of bound antibody were detected by incubation with biotinylated streptavidin horseradish peroxidase for one hour at room temperature, and a final incubation in substrate (Table 1) (Shu \& Fan 1988) for $20 \mathrm{~min}$ at room temperature. The reaction was stopped by rinsing the sections in $0.1 \mathrm{M}$ acetate buffer.

TABLE 1: Composition of substrate solution for immunoperoxidase reaction

\begin{tabular}{ll}
\hline Constituent & Quantity \\
\hline 3,3 Diaminobenzidine hydrochloride & $50 \mathrm{mg}$ \\
Distilled water & $50 \mathrm{~mL}$ \\
Ammonium nickel 2 sulphate & $2500 \mathrm{mg}$ \\
$0.2 \mathrm{M}$ acetate buffer, $\mathrm{pH} 6.0$ & $50 \mathrm{~mL}$ \\
$\beta$-D glucose & $200 \mathrm{mg}$ \\
Ammonium chloride & $40 \mathrm{mg}$ \\
Glucose oxidase type $(\mathrm{v})$ & $90 \mu \mathrm{L}$ \\
\hline
\end{tabular}

In all experiments, a negative control was run by substituting primary antibody with PBS. Labelling for the neuronal marker PGP gave consistent results and was therefore used as the positive control. The procedure employed for immunohistochemistry is summarised in Table 2.

For examination, sections were counterstained by immersion in eosin for clearer morphological definition. Coverslips were mounted using the resin Distren Xylene Plasticizer, DPX (Agar Scientific Company) after sections had been dehydrated by passing them through serial ethanol (50\%, $70 \%, 100 \%$ and $100 \%$ ) and immersion in the resin solvent xylene. All sections were examined under a standard light microscope at magnifications of 100-400. Whole mounts were evaluated and photomicrographs processed at final magnifications 125 and 500.

\section{Ethical considerations}

The study was conducted using non-living tissue obtained from surgical procedures carried out in the University of Liverpool Small Animal Hospital during routine clinical work. Results of the investigation were treated in confidentiality until submission of the manuscript.

\section{Results}

Polyclonal antiserum against C-kit gave no staining in any of the samples fixed in formaldehyde, most likely because of sensitivity of $\mathrm{C}-\mathrm{Kit}$ to the fixation process. However, application of goat anti-human C-Kit to unfixed sections successfully labelled ICC (Figures 1 and 2). Two classes of ICC were identified according to their distribution. One

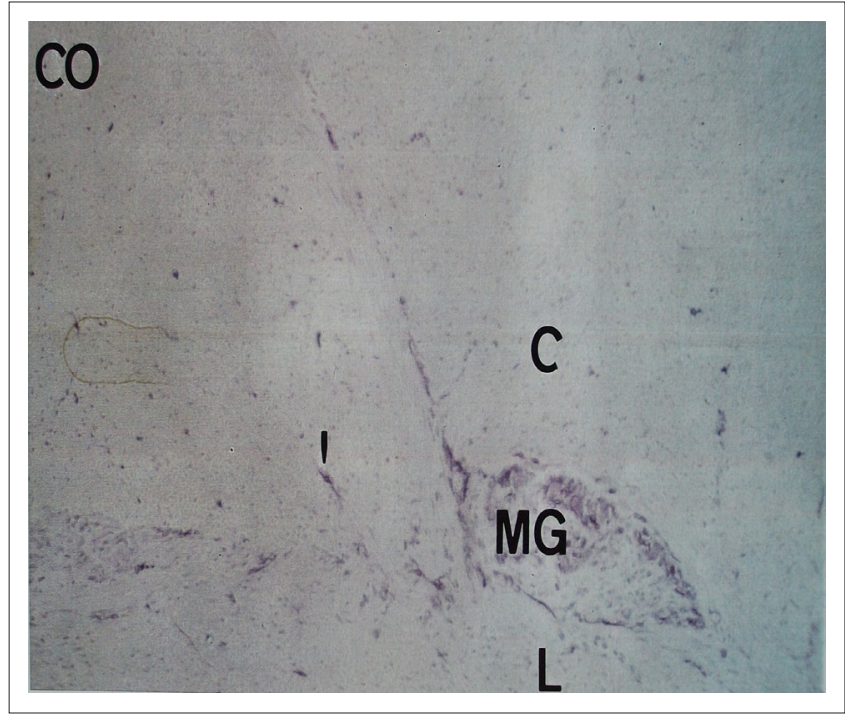

CO, corpus; C, circular smooth muscle; L, longitudinal smooth muscle; MG, myenteric ganglion. $\times 125$ magnification.

FIGURE 1: Overview of the density and distribution of ICC in the canine corpus.

TABLE 2: Markers and antibodies for immunohistochemical studies of the gastric motor-regulating system.

\begin{tabular}{llll}
\hline Component & Marker & Primary antibody & Secondary antibody \\
\hline Interstitial cells of Cajal & C-Kit & Polyclonal goat anti-human C-Kit (Santa Cruz) 1:20-1:200 & Rabbit anti-goat IgG biotin conjugate (Sigma) 1:50 \\
Enteric neurons & Protein Gene Peptide 9.5 & Polyclonal rabbit anti-human PGP (Ultracone) 1:1000 & Biotinylated goat anti-rabbit IgG (Sigma) 1:50 \\
Nitrergic neurons & Neuronal nitric oxide synthase & Sheep anti nNOS (Dr Emson) 1:1000 & Donkey anti-sheep IgG (Jackson Immunoresearch \\
& & & Laboratories) 1:50 \\
\hline
\end{tabular}




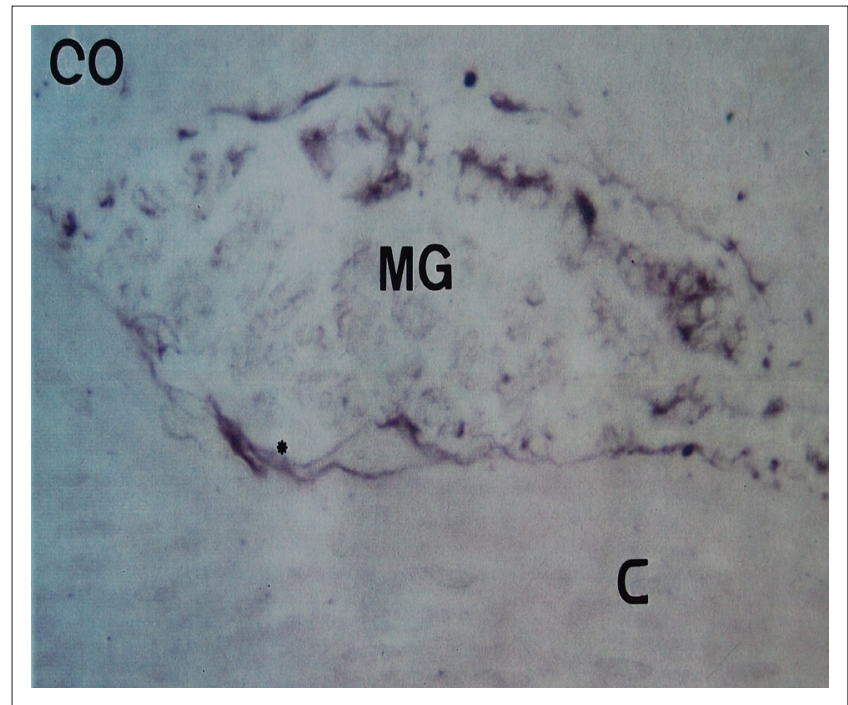

CO, corpus; C, circular smooth muscle; MG, myenteric ganglion. $\times 500$ magnification.

FIGURE 2: Distribution of ICC-MY at the periphery of myenteric ganglia in the corpus.

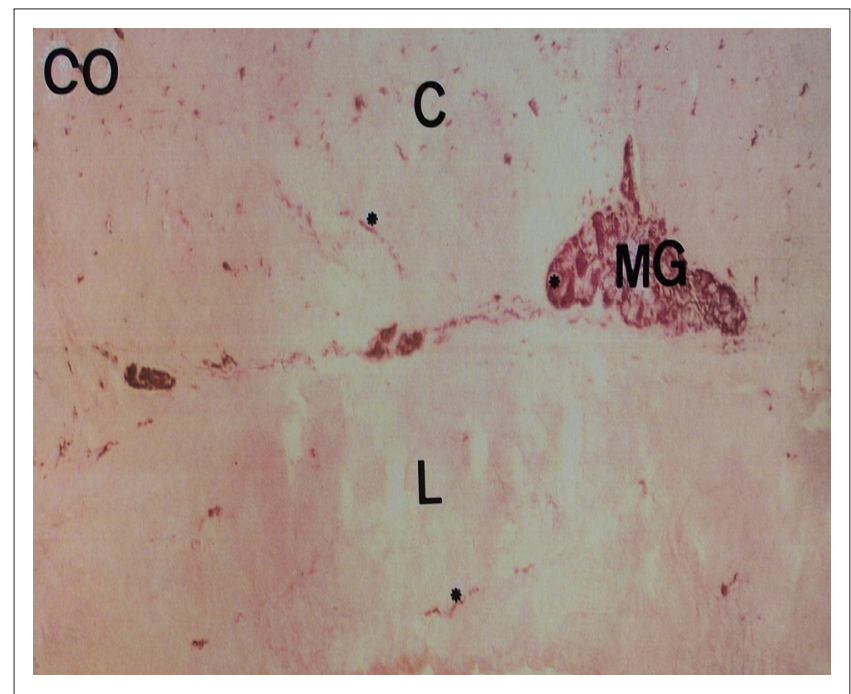

CO, corpus; C, circular smooth muscle; L, longitudinal smooth muscle; MG, myenteric ganglion. $\times 125$ magnification.

FIGURE 3: Relative density of nerve fibres in the circular and longitudinal muscle layers, as well as nerve cell bodies in the myenteric ganglia.

class of cells, known as ICC-MY, was distributed around the periphery of myenteric ganglia and at the level of the myenteric plexus. These cells were fusiform in shape and had relatively few processes. The other class of ICC comprised a population of stellate cells diffusely distributed in the circular and longitudinal muscle layers.

Neurons in the corpus and antrum of the stomach were consistently labelled by antibodies raised against the general neuronal marker PGP (Figures 3 and 4). In all samples, coarse bundles of fibres were observed in the serosa, myenteric plexus and submucosa. Nerve cell bodies were scattered between nerve bundles within the myenteric ganglia. Individual nerve fibres rather than bundles were more common within the mucosa and circular as well as longitudinal muscle layers. Fibre density was highest in the circular muscle layer as compared to the longitudinal muscle layer. Several cell bodies were observed in the myenteric ganglia interspersed

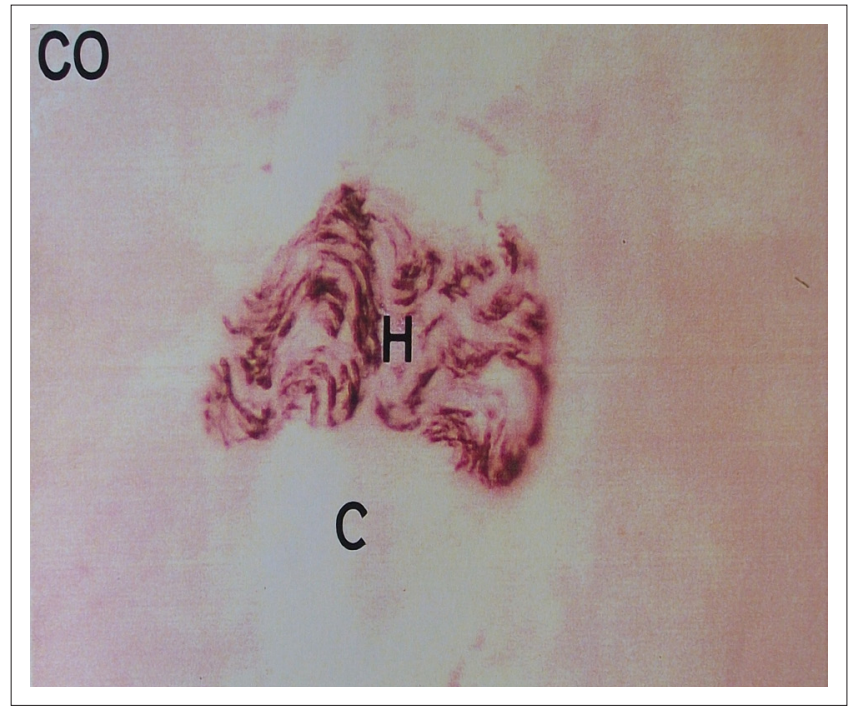

CO, corpus; C, circular smooth muscle; $\mathrm{H}$, typical nerve bundle. $\times 500$ magnification.

FIGURE 4: A typical nerve bundle in the circular smooth muscle of the corpus.

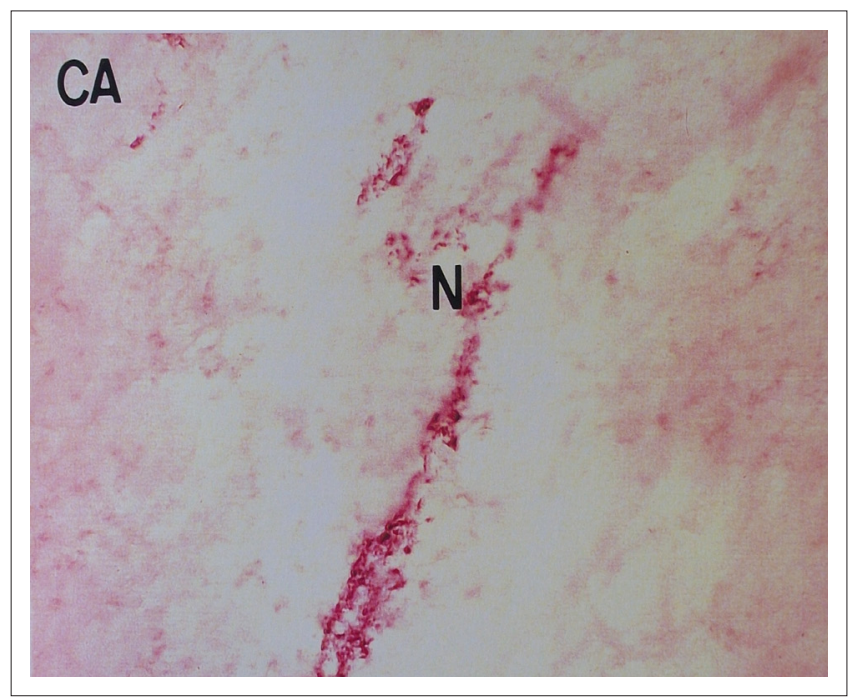

$\mathrm{CA}$, antrum; N, nitrergic nerve fibres.

$\times 500$ magnification.

FIGURE 5: Normal density and distribution of nitrergic nerve fibres in the circular smooth muscle of the antrum.

between bundles of nNOS-positive fibres. Nerve fibres with nNOS-like immunoreactivity were also diffusely distributed throughout the circular and longitudinal muscle layers, either singly or in small groups (Figure 5).

\section{Discussion}

In the past, a number of techniques have been used in the morphological study of ICC. The earliest of these procedures employed methylene blue and zinc iodide-osmic acid stains. However, these were of limited use, largely because of lack of specificity and the requirement for fresh tissue (Christensen 1992). Later on, electron microscopy became the method of choice for visualisation of ICC (Sanders 1996). Recently, immunohistochemical methods that demonstrate the presence of specific proteins have become useful in the morphological identification of ICC (Bernadini et al. 2012). Prior to the present study, no single histochemical or 
immunohistochemical method labelled ICC in the canine stomach with sufficient accuracy and consistency. The receptor tyrosine kinase (C-Kit) has been detected in ICC in man (Vanderwiden et al. 1996) and mice (Huizinga et al. 1995), amongst other species. C-Kit is a large protein of molecular weight about 160 kilodalton. In this study, ICC was labelled by polyclonal goat anti-human C-Kit (Santa Cruz Biotechnology). Staining for C-Kit in unfixed sections of the stomach revealed an overview of the density and distribution of ICC in the circular smooth muscle, myenteric ganglia and longitudinal smooth muscle at $\times 125$ magnification. At higher magnification $(\times 500)$, cell morphology and size could be clearly defined.

Assessment of the density, distribution and architecture of nerve fibres and cell bodies of the enteric nervous system has been used in diagnosis of neurological motor deficits such as Hirschsprung's disease in humans (Cotran, Kumar \& Robbins 1994). In the present investigation, all three morphological features were well-defined. Reduction of non-adrenergic inhibitory nerves has been identified as a cause of impaired motility observed in some cases of diminished nerve fibre density (Tomita, Munakata \& Korusu 1994). Since nitrergic nerves form a major component of inhibitory nerves of the gastrointestinal tract, the investigation was extended to ascertain the morphological features of nitric oxide-producing neurons in the stomach. Staining for nNOS revealed a large component of nitrergic nerves in the circular smooth muscle. This finding supports the growing concept that inhibitory motor control makes an important contribution to normal motor function in the gastrointestinal tract.

In conclusion, observations made in the present study lend weight to the paradigm that in considering the gastrointestinal motor system, attention should be drawn to all three (instead of just two) components, namely, smooth muscle, neurons and ICC.

\section{Conclusion}

Owing to their specificity, immunohistochemical methods cannot be readily extrapolated from one species to another. In the present study, gastric ICC and enteric neurons in the dog were successfully labelled using antibodies raised against goat anti-human C-Kit, PGP 9.5 and nNOS. Thus the density and distribution of enteric neurons and ICC in the canine stomach were revealed. Immunohistochemical methods are a valuable diagnostic tool in that they allow comparison of the morphology of the motor-regulating system between normal animals and those with gastric motor dysfunction. In future, application of electrophysiological techniques would be necessary to complement diagnostic effort from immunohistochemistry.

\section{Acknowledgements}

We would like to thank the European Union for funding this research work through the UZ-University of Liverpool link programme.

\section{Competing interests}

The authors declare that they have no financial or personal relationship(s) which may have inappropriately influenced them in writing this article.

\section{Authors' contributions}

C.M. (University of Zimbabwe) conducted all experiments and C.V. (University of Liverpool) provided research materials, equipment and laboratory. The manuscript was a joint effort of both authors.

\section{References}

Bernardini, N., Segnani, C., Ippolito, C., De Giorgio, R., Colucci, R., Fousonne-Pellegrini, S. et al., 2012, 'Immunohistochemical analysis of myenteric ganglia and interstitia cells of Cajal in ulcerative colitis', Journal of Cellular and Molecular Medicine 16(2) 318-327. http://dx.doi.org/10.1111/j.1582-4934.2011.01298.x, PMid:21426484

Bredt, D.S. \& Snyder, S.H., 1990, 'Localisation of nitric oxide synthase indicating a neuronal role of nitric oxide', Nature 87, 682-685.

Burns, A., Lomax, A.E., Torihashi, S., Sanders, K.M. \& Ward, S.M., 1996, 'Interstitial cells of Cajal mediate inhibitory neurotransmission in the stomach', Proceedings of the National Academy of Science USA 93, 12008-12013. PMid:8876253

Burrows, C.F. \& Ignazewski, L.A., 1990, 'Canine gastric-dilatation-volvulus', Journal of Small Animal Practice 31, 495-501. http://dx.doi.org/10.1111/j.1748-5827.1990. tb00671.x

Christensen, J., 1992, 'A commentary on the morphological identification of interstitial cells of Cajal in the gut', Journal of the Autonomic Nervous System 37, 75-88. http://dx.doi.org/10.1016/0165-1838(92)90236-A

Cotran, R.S., Kumar, V. \& Robbins, S.L., 1994, Pathologic basis of disease, W.B. Saunders and Company, Philadelphia, London, Toronto, Montreal, Sydney, Tokyo. PMid:7911822

Hall, A.J., Sollie, T.N., Seim III, H.B. \& Twedt, D.C., 1993, 'Gastric myoelectric and motor activity in dogs with gastric-dilatation-volvulus', American Journal of Physiology 265(4 Part 1), G646-G653. PMid:8238348

Huizinga, J.D., Thuneberg, L., Kluppel, M., Malysz, J., Mikkelsen, H.B. \& Bernestein, A., 1995, 'W/Kit gene required for development of interstitial cells of Cajal and or intestinal pacemaker activity', Nature 373, 347-349. http://dx.doi.org/10.1038/ 373347a0, PMid:7530333

Krammer, H.J., Karahan, S.T., Rumpel, E., Klinger, M. \& Kuhnel, W., 1993, 'Immunohistological visualization of the enteric nervous system using antibodies against protein gene peptide 9.5', Anatomy-Anz 175(4), 321-325. http://dx.doi.org/10.1016/S0940 9602(11)80029-4

Li, C.G. \& Rand, M.J., 1990, 'Nitric oxide and vasoactive intestinal polypeptide mediate non-adrenergic, non-cholinergic transmission to smooth muscle in the rat gastric non-adrenergic, non-cholinergic transmission to smooth muscle in the rat gastric
fundus', European Journal of Pharmacology 191, 303-309. http://dx.doi.org/10.1016/ fundus', European Journal
0014-2999(90)94162-Q

Lyford, G.L., He, C-L., Soffer, E., Hull, T.L., Strong, S.A., Senagore, A.J. et al., 2002, 'Pancolonic decrease in interstitial cells of Cajal in patients with slow transit constipation', Gut 51, 496-501. http://dx.doi.org/10.1136/gut.51.4.496, PMid:12235070

Moncada, S., Palmer, R.M. \& Higgs, E.M., 1991, 'Nitric oxide: Physiology, pathophysiology and pharmacology', Pharmacological Reviews 43(2), 109-134. PMid:1852778

Rottapel, R., Reeduck, M., Williams, D.E., Lyman, S.D., Andersen, D.M., Pawson, T. et al., 1995 , 'The steel/W transduction pathway: Kit autophosphorylation and its association with a unique set of cytoplasmic signaling proteins is induced by the steel factor', Molecular Cell Biology 11, 3043-3051.

Sanders, K.M., Don Koh, S. \& Ward, S.M., 2006, 'Interstitial cells of Cajal as pacemakers in the gastrointestinal tract', Annual Review of Physiology 68, 307-343. http:// dx.doi.org/10.1146/annurev.physiol.68.040504.094718, PMid:16460275

Sanders, K.M., 1996, 'A case for interstitial cells of Cajal as pacemakers and mediators of neurotransmission in the gastrointestinal tract', Gastroenterology 111, 492-515. http://dx.doi.org/10.1053/gast.1996.v111.pm8690216, PMid:8690216

Shu, S., Ju, G. \& Fan, L., 1988, 'The glucose oxidase-DAB nickel method in the peroxidase histochemistry of the nervous system', Neuroscience Letters 85, 169-171. http:// dx.doi.org/10.1016/0304-3940(88)90346-1

Thompson, J.R., Doran, J.F., Jackson, P., Dillion, A.P. \& Rhode, J., 1983, 'PGP 9.5 - A new marker for vertebrate neurones and neuroendocrine cells', Brain Research 278 224-228. http://dx.doi.org/10.1016/0006-8993(83)90241-X

Tomita, R., Munakata, K. \& Korusu, Y., 1994, 'Peptidergic nerves in Hirschsprung's disease and its allied disorders', European Journal of Paediatric Surgery 4(6), 346-351. http://dx.doi.org/10.1055/s-2008-1066132, PMid:7538322

Vanderwiden, J.M., Liu, H., De Laet, H.M. \& Vanderhaeghen, J.J., 1996, 'Study of interstitial cells of Cajal in infantile hypertrophic pyloric stenosis', Gastroenterology 111, 279-288. http://dx.doi.org/10.1053/gast.1996.v111.pm8690192

Ward, S.M., Burns, A.J., Torihashi, S., Harney, S.C. \& Sanders, K.M., 1995, 'Impaired development of interstitial cells and intestinal rhythmicity in steel mutants', American Journal of Physiology 269, C1577-C1585. PMid:8572188 